\title{
Má Compactação do Ventrículo Esquerdo - Diagnóstico Otimizado pela Ecocardiografia Tridimensional em Tempo Real
}

Poor Left Ventricle Compaction - Diagnosis Optimized by Real-time Three-Dimensional Echocardiography

Gabriel Antonio Stanisci Miguel e Henry Abensur

Real e Benemérita Associação Portuguesa de Beneficência de São Paulo - São Paulo, SP - Brasil

Paciente com 37 anos, do sexo masculino, com diagnóstico de má compactação ventricular esquerda. O ecocardiograma bidimensional demonstrou extensas trabeculações associadas à formação de sinusóides no interior do ventrículo esquerdo, evidenciados pelo mapeamento de fluxo em cores. A ecocardiografia tridimensional em tempo real confirmou esses achados, ressaltando a presença de trabeculações numerosas, excessivamente proeminentes e de profundos recessos intertrabeculares, sobretudo na região apical.

Em casos com janela acústica limitada, o exame tridimensional poderia permitir maior riqueza de detalhes por meio da visibilização de estruturas cardíacas pela composição de múltiplos planos observacionais, ressaltando informações morfológicas e funcionais (fig. 1).

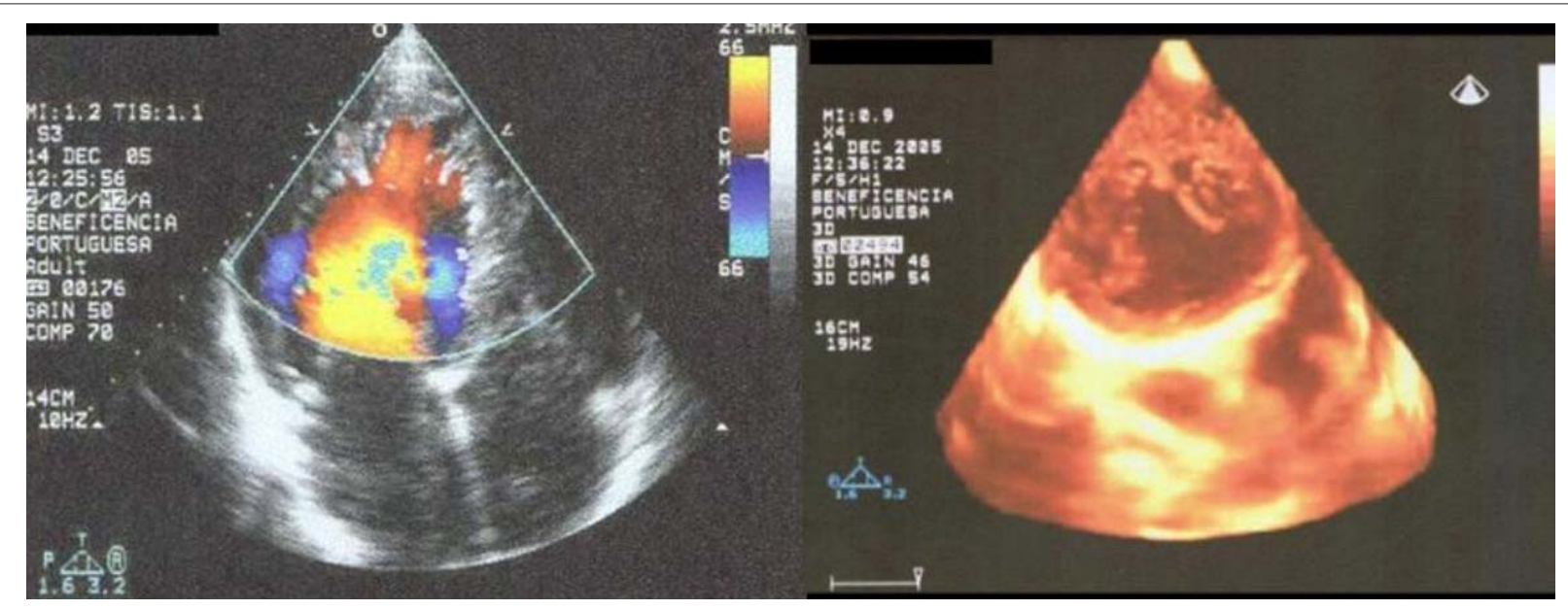

Fig. 1 - À esquerda, ecocardiograma bidimensional transtorácico (projeção apical quatro câmaras), demonstrando sinusóides evidenciados pelo mapeamento de fluxo em cores. À direita, ecocardiograma tridimensional transtorácico em tempo real (projeção apical), demonstrando numerosas trabeculações associadas aos recessos intertrabeculares (sinusóides trabeculares) no interior do ventrículo esquerdo.

\section{Palavras-chave}

Ecocardiografia, ventrículos cardíacos/anatomia e histologia.

Correspondência: Gabriel Antonio Stanisci Miguel •

Rua Santa Madalena, 290/131 - 01322-020 - São Paulo, SP - Brasil

E-mail: gasmiguel@cardiol.br

Artigo recebido em 13/11/06; revisado recebido em 16/02/07; aceito em

13/03/07. 